\title{
Qualität durch Seelsorge
}

\author{
Seit 1. April 2021 führen die Grazer Elisabethinen zwei \\ Standorte, die besonders auch durch die Krankenhaus- \\ seelsorge geprägt werden.
}

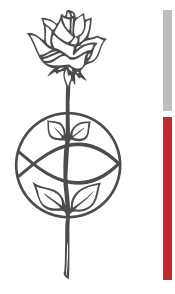

\section{die elisabethinen}

gesundheit \& leben

W ir tun unseren Dienst, damit der ganze Mensch heil wird." Dieses Mutwort aus der Charta der Elisabethinen in Österreich (2017) gibt ihren Diensten und Leistungen eine besondere Sinnspitze. Besonders auch in herausfordernden Zeiten steht der Mensch in allen seinen Dimensionen, mit seinen Hoffnungen, Sorgen und Nöten im Mittelpunkt ihres Wirkens.

Die Seelsorge ist somit für das gemeinnützige Akutkrankenhaus, das vom Orden der Elisabethinen getragen wird, ein grundlegendes Charakteristikum im Panorama des umfassenden Engagements für die Patientinnen und Patienten und eine Kompassnadel für die Lebendigkeit seiner DNA. „Kompetenz auf der Höhe der Zeit braucht man immer, entscheidend ist jedoch die Haltung, also sozusagen der Versuch, auf der Höhe der heiligen Elisabeth zu bleiben“, wie Generaloberin und Geschäftsführerin Mutter Bonaventura Holzmann in einem Interview sagte.

Das Angebot der Krankenhausseelsorge bei den Elisabethinen steht allen Patienten unabhängig von ihrer Religionszugehörigkeit oder von ihrem persönlichen Glauben offen. Auf Wunsch der Patienten vermittelt das Team der katholischen Seelsorge auch einen Kontakt hin zur jeweiligen anerkannten Religionsgemeinschaft. Die Seelsorge ist ein besonderer Bezugspunkt in der Prägung des neuen, zweiten Standortes des Krankenhauses der Elisabethinen in GrazEggenberg. In Eggenberg übernahmen die Elisabethinen mit 1. April 2021 von den

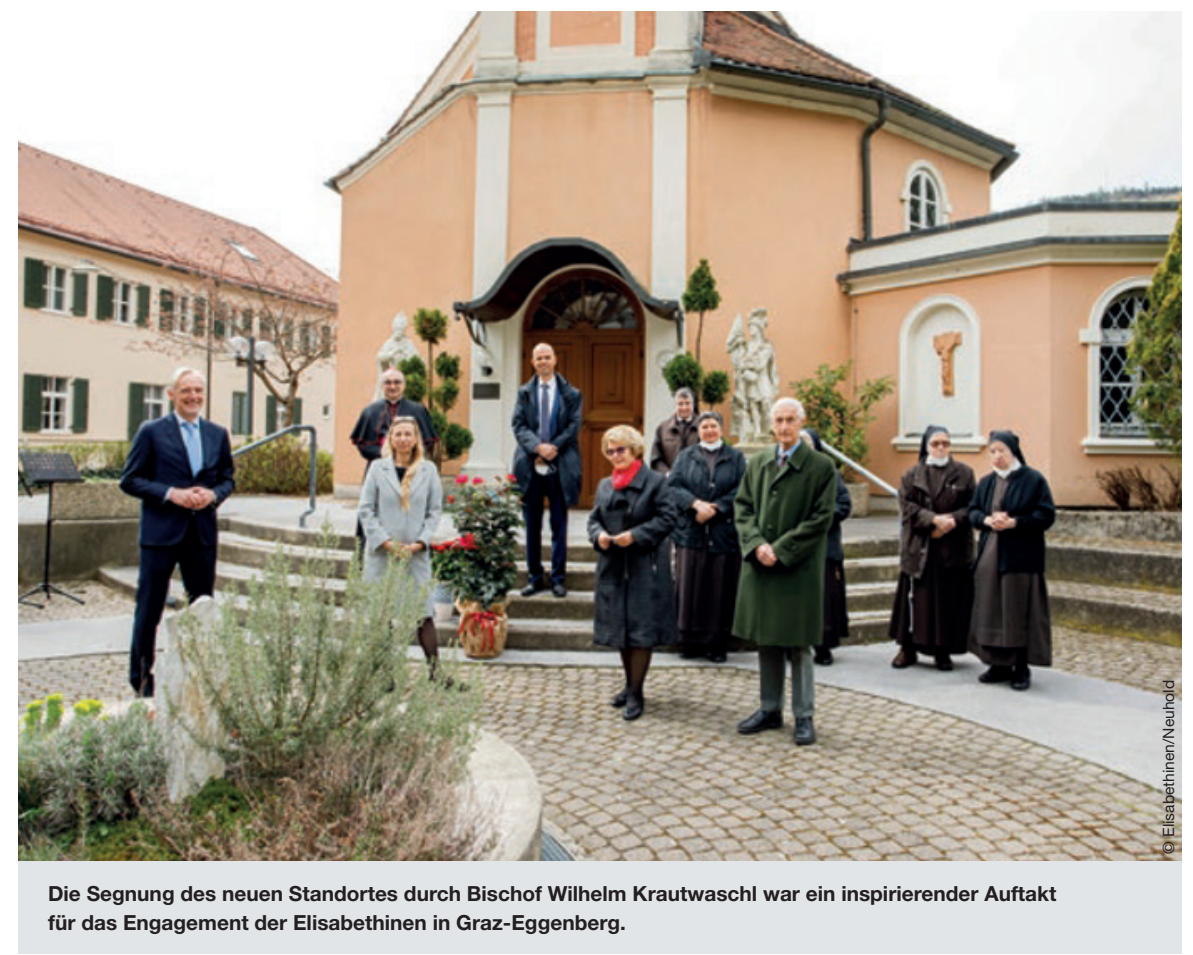

Barmherzigen Brüdern die Abteilung für Psychiatrie und Psychotherapie, die Abteilung für Neurologie und erhielten darüber hinaus den Versorgungsauftrag für Alterspsychiatrie im Großraum Graz.

Mit der Segnung des zweiten Krankenhausstandortes durch den steirischen Bischof Dr. Wilhelm Krautwaschl am 12. April 2021 erhielt die franziskanische Ordensgemeinschaft vertiefte geistliche Impulse für einen dynamischen Start in Eggenberg. Bei diesem Gottesdienst unter freiem Himmel waren auch Juliane Bogner-Strauß, steirische Landesrätin für
Bildung, Gesellschaft, Gesundheit und Pflege, und Günter Riegler, Stadtrat der Landeshauptstadt Graz für Kultur, Wissenschaft und Finanzen, anwesend. Der Grazer Altbürgermeister Alfred Stingl gab dabei den Elisabethinen Gedanken für eine zukunftsfitte Psychiatrie im Alter mit auf den Weg.

Autor:

Mag. Peter Rosegger, MBA

Leiter Wirkfeld „Iernen\&leben“

und Öffentlichkeitsarbeit

die elisabethinen graz gmbh

peter.rosegger@elisabethinen.at 